\title{
Stability of HIV-1 subtype B and C Tat is associated with variation in the carboxyl-terminal region
}

\author{
Xuechao Zhao, Lingyu Qian, Deyu Zhou, Di Qi, Chang Liu, Xiaohong Kong \\ Laboratory of Medical Molecular Virology, School of Medicine, Nankai University, Tianjin 300071, China
}

The multifunctional trans-activator Tat is an essential regulatory protein for HIV-1 replication and is characterized by high sequence diversity. Numerous experimental studies have examined Tat in HIV-1 subtype B, but research on subtype C Tat is lacking, despite the high prevalence of infections caused by subtype $C$ worldwide. We hypothesized that amino acid differences contribute to functional differences among Tat proteins. In the present study, we found that subtype B NL4-3 Tat and subtype C isolate HIV1084i Tat exhibited differences in stability by overexpressing the fusion protein Tat-Flag. In addition, 1084i Tat can activate LTR and NF-KB more efficiently than NL4-3 Tat. In analyses of the activities of the truncated forms of Tat, we found that the carboxylterminal region of Tat regulates its stability and transactivity. According to our results, we speculated that the differences in stability between B-Tat and C-Tat result in differences in transactivation ability.

\section{KEYWORDS Tat; subtype B/C; stability; transactivation; carboxyl-terminal region; NF-kB activation}

\section{INTRODUCTION}

The epidemic patterns of HIV-1 subtypes are continuously evolving, and subtypes $\mathrm{B}$ and $\mathrm{C}$ are dominant (accounting for approximately $60 \%$ of infections). Subtype $\mathrm{B}$ accounts for just a little more than $12 \%$ of infections worldwide and more than half of HIV infections worldwide are caused by subtype C (Geretti, 2006). Nevertheless, subtype B, found predominantly in the United States and Europe, is the most widely studied. Therefore, studies of subtype $\mathrm{C}$ should be a priority (Saxena et al., 2012). There are substantial differences between subtype B and C HIV, including sequence, structural, and antigenic variation (Saiyed et al., 2011), each of which can influence the biological properties of the virus, susceptibility to existing and candidate antiretroviral drugs, and evolution of antiretroviral drug resistance (Cohen,

Received: 20 November 2015, Accepted: 1 March 2016,

Published online: 21 March 2016

$\square$ Correspondence:

Phone: +86-022-23504347, Fax: +86-022-23499505,

Email: kongxh@nankai.edu.cn

ORCID: 0000-0002-2543-9066
2012). These differences also imply that the treatment approach for the subtype B virus may not be directly applicable to subtype C (Cohen, 2012; Saxena et al., 2012). In fact, subtype C HIV appears to be transmitted more efficiently than the other subtypes (Essex, 1999). Therefore, it is of great importance to examine differences in pathogenic potency among these subtypes to understand the genetic and functional characteristics of these viruses.

The HIV-1 trans-activator Tat protein is essential for virus replication and the progression of HIV infection. Therefore, understanding functional differences in Tat between subtype $\mathrm{B}$ and $\mathrm{C}$ will provide important insight into the differential pathogenesis. Substantial amino acid variation has been observed among the clade-specific Tat proteins. Differences in conserved amino acids between $\mathrm{B}$-Tat and C-Tat may result in functional discrepancies. For example, C-Tat is less neurotoxic than B-Tat, probably as a result of alterations in the dicysteine motif within the neurotoxic region of B-Tat (Mishra et al., 2008). However, it is not clear whether there are other functional differences between B-Tat and C-Tat.

Tat is an $86-101$ residue regulatory protein (9-11 
$\mathrm{kDa}$ ) produced early in HIV-1 infection; it regulates productive and processive transcription from the HIV-1 long terminal repeat (LTR) (Loret et al., 1992; Karn, 1999; Gatignol and Jeang, 2000). The viral Tat mRNA is composed of two exons. The first exon encodes 72 amino acids (residues 1-72, hereafter Tat72) and contains three important functional regions: the cysteine-rich region (amino acids 22-37), the basic region (amino acids 49-57), and the glutamine-rich region (amino acids 58-72). The second exon encodes a variable number of amino acids (residues 14-29) that contribute to viral infectivity and other functions (Rana and Jeang, 1999).

Tat72 is generated in the late stage of the HIV-1 infection cycle. The 86-residue truncated form of Tat (hereafter Tat86), produced early in HIV-1 infection, is generated due to a premature stop codon within the second exon. Though the full-length form of Tat (i.e., the 101residue form, referred to as Tat101) is predominant in HIV-1 clinical isolates (Gibellini et al., 2005), Tat86 and Tat72 are used more widely for in vitro studies. Therefore, the extreme $\mathrm{C}$ terminus of Tat is not frequently examined, despite its demonstrated significance in several biological assays (Ott et al., 1997; Xiao et al., 1998; Smith et al., 2003; Campbell et al., 2005; Passiatore et al., 2009; Lopez-Huertas et al., 2010).

In this study, we compared the stability of Tat between subtype $\mathrm{B}$ and $\mathrm{C}$ and the ability of each to transactivate HIV-1 LTR and activate NF- $\kappa B$. We also assessed the effect of truncated forms of Tat on stability, LTR expression, and NF- $\kappa \mathrm{B}$ activity. We observed differences in stability between B-Tat and C-Tat; the latter was a significantly stronger transactivator of LTR expression and showed a greater ability to activate the transcription factor NF- $\mathrm{KB}$. The carboxyl-terminal region of Tat is involved in regulating the stability and transcriptional activity of Tat.

\section{MATERIALS AND METHODS}

\section{Plasmid construction}

NL4-3 Tat and 1084i Tat were amplified from the infectious molecular clone NL4-3 and an infectious molecular clone of a pediatric clade C strain, HIV1084i, which was isolated from a Zambian infant infected with HIV-1 (Grisson et al., 2004), by overlapping polymerase chain reaction (PCR). The PCR products were inserted into the Bam HI-XhoI sites of the mammalian expression vector pcDNA3.1 to create pcDNA3.1-Tat-Flag. The truncated forms, CTat86-Flag, CTat72-Flag, and BTat72-Flag were generated by insertion of the cDNA fragments into the pcDNA3.1 vector. The NL4-3 LTR was amplified from infectious molecular clone NL4-3, and then inserted into the KpnI-XhoI site of the pGL3-Basic Vector.

\section{Cell culture and transfection}

HEK293 T cells were maintained in Dulbecco's modified Eagle's medium (DMEM) with 10\% fetal bovine serum (FBS), penicillin $(50 \mathrm{U} / \mathrm{mL})$, and streptomycin (50 $\mathrm{mg} / \mathrm{mL}$ ) at $37^{\circ} \mathrm{C}$ in humidified air with $5 \% \mathrm{CO}_{2}$. Transfection was performed using polyethyleneimine (1 $\mathrm{mg} / \mathrm{mL}$ ) (Sigma, St. Louis, USA) and corresponding plasmids. In brief, for each 24-well plate, $1.0 \times 10^{5} 293 \mathrm{~T}$ cells were seeded with DMEM containing 10\% FBS for $20 \mathrm{~h}$ before transfection. Less than $1 \mu \mathrm{g}$ of plasmid DNA was suspended in $100 \mu \mathrm{L}$ of DMEM in a polystyrene tube, and polyethyleneimine ( $3 \mu \mathrm{L}$ for $293 \mathrm{~T}$ ) was added and immediately mixed before incubation for $10 \mathrm{~min}$ at room temperature. Thereafter, the mixture was distributed gently onto the cell culture and incubated at $37^{\circ} \mathrm{C}$ in humidified air with $5 \% \mathrm{CO}_{2}$. The medium was exchanged with complete medium (DMEM supplemented with FBS and antibiotics) $8 \mathrm{~h}$ later.

\section{Protein translation arrest}

HEK293T cells transfected with pcDNA3.1-Tat-Flag were treated 24 -h post-transfection with medium containing $200 \mu \mathrm{g} / \mathrm{mL}$ cycloheximide (CHX) (Sigma-Aldrich). Cells were harvested at $0,2,4,6,8$, and $10 \mathrm{~h}$ posttreatment, and western blotting was performed on lysates. Band (pixel) intensities were quantified using ImageJ and corrected for background levels by sampling an empty area. The mean natural log values of band intensities (from three independent experiments) were plotted against time. Tat-Flag half-life was determined mathematically by fitting values to the linear-transformed exponential-decay formula: $\ln (y)=\ln (b)-a t$, where $y$ is the Tat-Flag band intensity at time $t, b$ is the initial Tat-Flag band intensity at $0 \mathrm{~h}$, and $a$ is the decay constant and is equivalent to the slope of the curve.

\section{Luciferase reporter assays}

HEK293T cells grown in 24-well plate wells were cotransfected with $100 \mathrm{ng}$ of pLTR-luc or $3 \kappa \mathrm{K}$-luc and 20 ng of pRL-SV40, with or without $200 \mathrm{ng}$ of pcDNA3.1Tat-Flag. The cell medium was replaced with fresh medium $6 \mathrm{~h}$ after transfection. After transfection for $48 \mathrm{~h}$, luciferase activity was measured using the Steady-Glo Luciferase Assay System (Promega, Madison, USA). Luciferase activity was normalized to Renilla luciferase activity. The data are presented as means $\pm \operatorname{SD}(n=3)$.

\section{Quantitative real-time PCR analysis}

HEK293T cells transfected with CTat101-Flag, CTat86Flag, CTat72-Flag, BTat86-Flag, and BTat72-Flag were treated with $(+)$ or without $(-)$ MG132. Total RNA was isolated from cells using TRIzol reagent (Invitrogen, Carlsbad, USA) according to the manufacturer's instructions. The isolated RNA was reverse-transcribed into 
cDNA using reverse transcriptase (Promega). Real-time PCR was performed using the SYBR Green PCR Kit (TAKARA, Kusatsu, Japan) and a Real-Time PCR Detection System (BIO-RAD IQ2; Hercules, CA, USA). A melting curve analysis was performed to ensure the amplification of a single product. The following primers were used: BTat-F, 5'-GACTAGAGCCCTGGAAGCA TC-3'; BTat-R, 5'-CCATAGGAGATGCCTAAGGC-3'; CTat-F, 5'-CTAGAGCCCTGGAATCATCC-3'; CTat-R, 5'-CCATAGGAAATGCCTAAGC-3'; GAPDH-F, 5'ATCACTGCCACCCAGAAGAC-3'; GAPDH-R, 5'ATGAGGTCCACCACCCTGTT-3'.

\section{RESULTS}

The different stabilities of NL4-3 Tat and 1084i Tat The half-life of Tat was studied by a CHX chase assay. CHX treatment has been used to determine the half-lives of several proteins, including Tat (Lata et al., 2015). HEK293T cells expressing Tat-Flag (Figure 1A) were treated with $\mathrm{CHX}$ and harvested at various time points.

A pcDNA3.1-Tat-Flag_— Flag

B
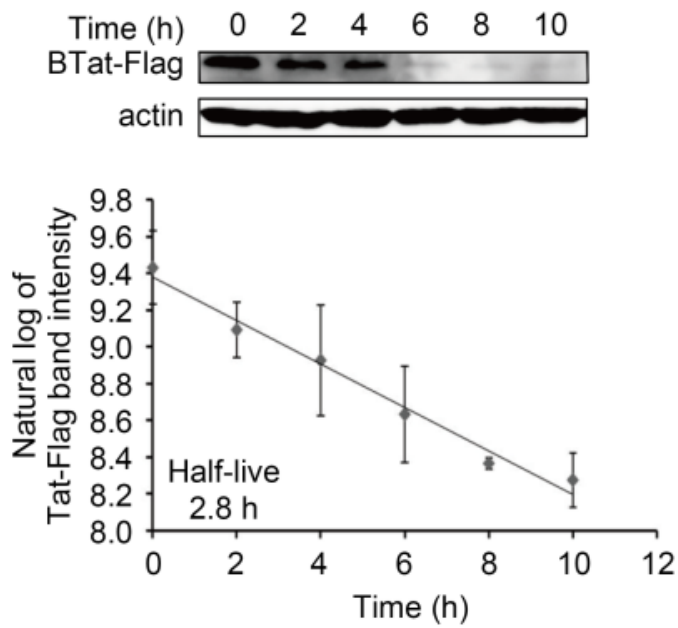

C

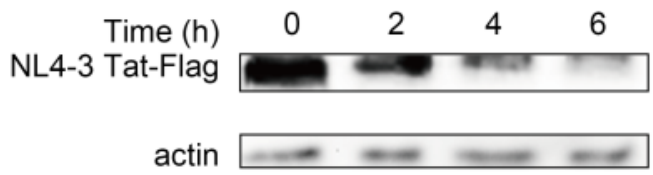

Western blotting was then performed on the cell lysates. As shown in Figure 1B, the half-life of NL4-3 Tat (1-86, B-Tat) was $2.8 \mathrm{~h}$, in fair agreement with the results of Sivakumaran et al. (2009). However, the half-life of 1084i Tat (1-101, C-Tat) was $5.5 \mathrm{~h}$, which was twice of NL4-3 Tat. In addition, we examined the stability of Tat in Jurkat cells. The half-life of 1084i Tat was longer than that of NL4-3 Tat, similar to the results for HEK293T cells (Figure 1C)

\section{The carboxyl-terminal region of Tat regulates stability}

Given that 1084i Tat is 15 amino acids longer than NL43 Tat in the C-terminal region, we examined whether the $\mathrm{C}$-terminal region of $1084 \mathrm{i}$ Tat affects stability. Figure $2 \mathrm{~A}$ shows that the half-life of the truncated CTat 86 was $3.8 \mathrm{~h}$. The stability of CTat 86 was slightly lower than that of C-Tat, but it was still more stable than NL4-3 Tat. We also observed that the half lives of BTat72 and CTat72 (the first exon form of Tat) were $1.6 \mathrm{~h}$ and $2.4 \mathrm{~h}$, respectively (Figure 2A-2D). These results suggest that
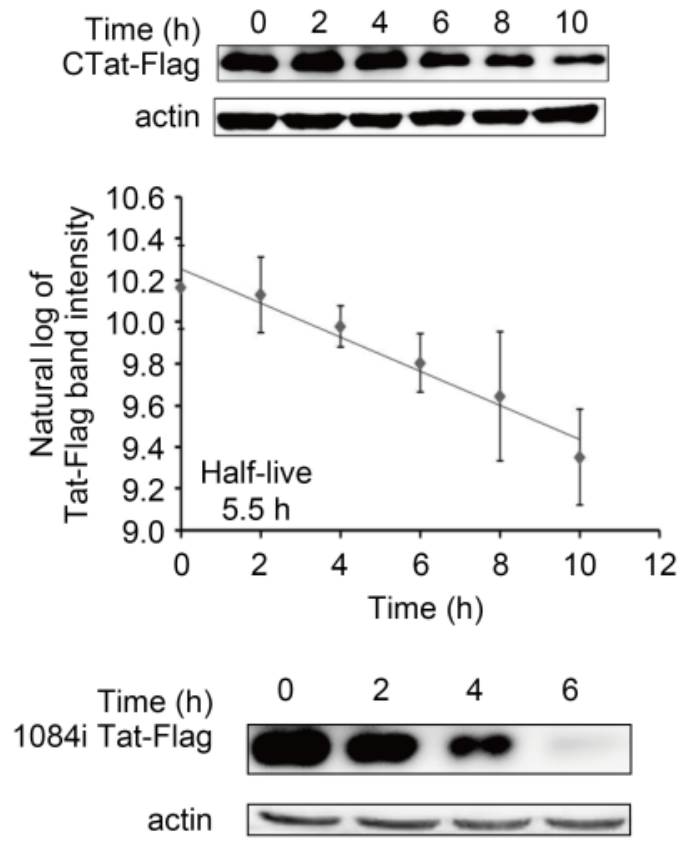

Figure 1. The different stabilities of NL4-3 Tat and 1084i Tat in HEK293T cells. (A) Schematic representation of TatFlag-expressing plasmids. The cDNAs of NL4-3 Tat-Flag and 1084i Tat-Flag were inserted into the BamHI-Xhol sites of the mammalian expression vector pcDNA3.1 (+) to create pcDNA3.1-Tat-Flag-expressing plasmids. (B) HEK293T cells expressing Tat-Flag were treated with $\mathrm{CHX}$ and harvested at $0,2,4,6,8$, and $10 \mathrm{~h}$ post-treatment. Western blotting was performed on the total-protein-equalized lysates. The actin levels show equivalent sample loadings. The Tat-Flag band intensities were quantified using ImageJ, and their natural log values were plotted as a function of time. The calculated Tat-Flag half-life is shown. The data points represent the means and standard deviations of three independent experiments. (C) The half-life of Tat-Flag was examined in Jurkat cells. 
A

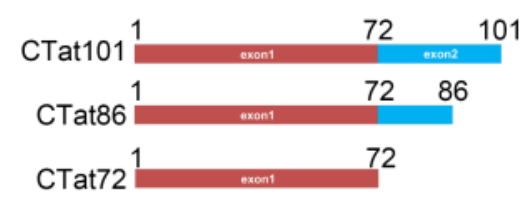

B

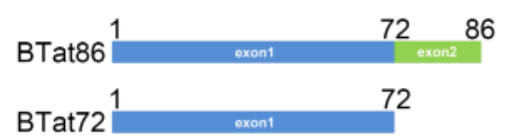

C

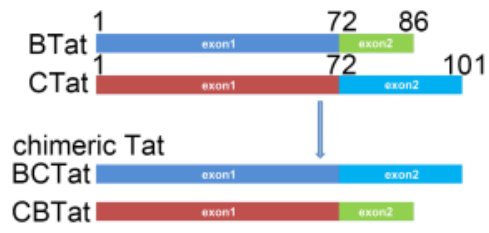

$\begin{array}{lllllll}\text { Time }(\mathrm{h}) & 0 & 2 & 4 & 6 & 8 & 10\end{array}$ CTat86-Flag $-\ldots$
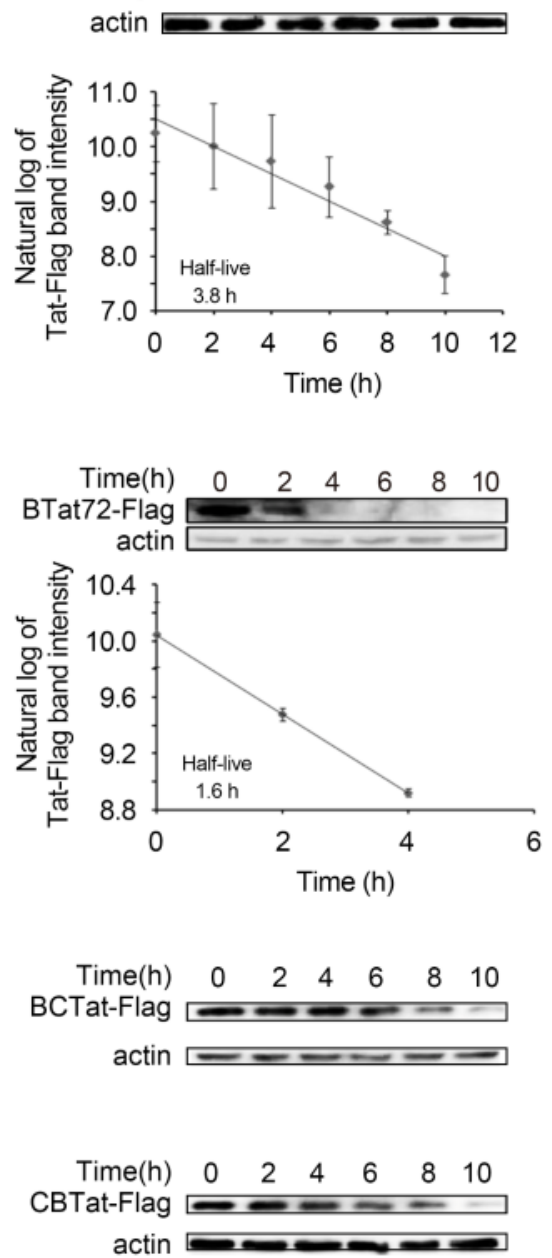

$\begin{array}{lllllll}\text { Time(h) } & 0 & 2 & 4 & 6 & 8 & 10\end{array}$
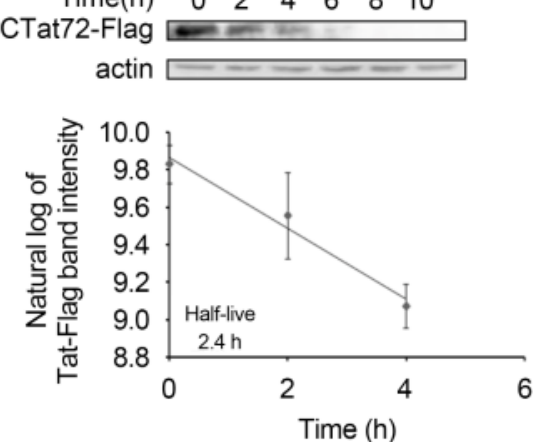

D

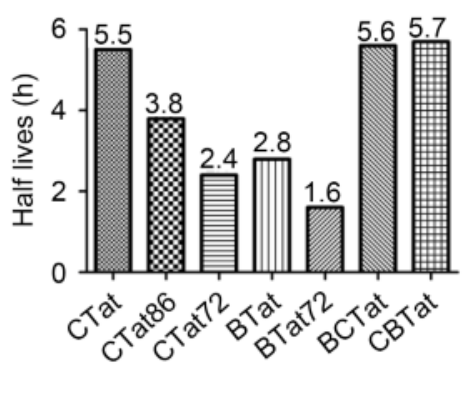

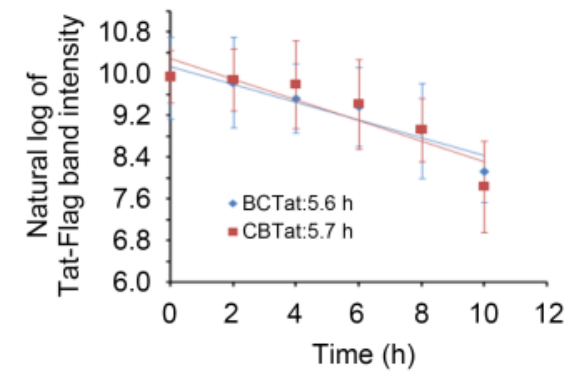

Figure 2. The carboxyl-terminal region of Tat regulates stability. (A, B, C) The half-lives of C-Tat, B-Tat, the carboxylterminal region deletion mutants, and chimeric Tat were determined. (D) Comparison of half-lives of different Tat mutants.

the carboxyl-terminal region truncation makes Tat fragile and sensitive to degradation. Collectively, these results demonstrate that the stability of B-Tat and C-Tat were both modulated by their carboxyl-terminal regions and C-Tat was more stable than B-Tat.

It is possible that the amino acid differences in the carboxyl-terminal region between NL4-3 Tat and 1084i Tat contribute to the observed differences in protein stability. We generated chimeric Tat proteins by swapping the clade-specific carboxyl-terminal regions (Figure 2C). Replacement of the NL4-3 Tat carboxyl-terminal region with the 1084i Tat carboxyl-terminal region resulted in enhanced stability of the chimeric BC-Tat $(5.6 \mathrm{~h})$ compared to B-Tat. However, the half-life of chimeric CBTat $(5.7 \mathrm{~h})$ was similar to that of C-Tat. This finding in- dicated that the specific domain of C-Tat is not responsible for the increased protein stability.

\section{The proteasome-dependent Tat degradation pathway was influenced by the carboxyl- terminal region of Tat}

Tat is degraded by an ubiquitin-independent proteasomal pathway (Sivakumaran et al., 2009). HEK293T cells expressing Tat-Flag were treated with the proteasome inhibitor MG132, and this treatment substantially increased the stability of B-Tat and C-Tat (Figure 3A, 3D), clearly demonstrating that proteasome activity is required for Tat degradation. Moreover, for CTat101, MG132 treatment resulted in a significant increase (2.1fold) in Tat-Flag compared to vehicle-treated controls, as 
A

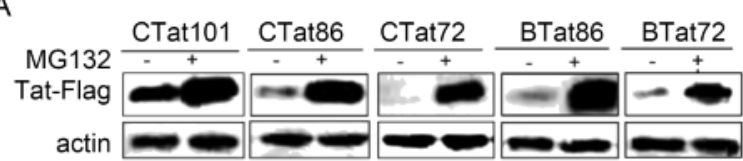

B

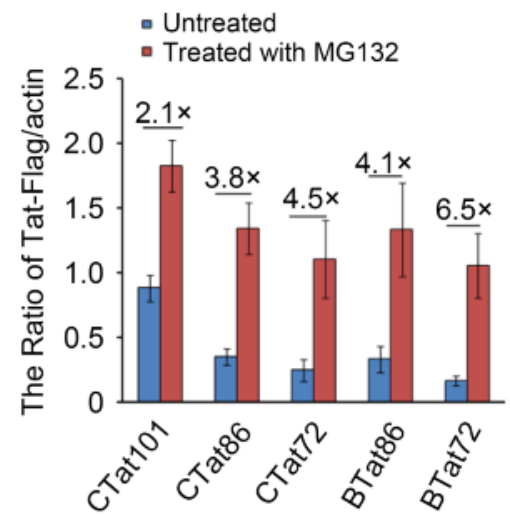

C

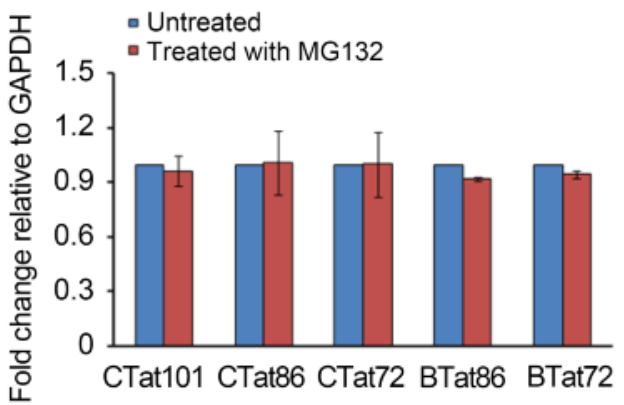

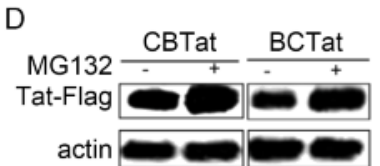

$\mathrm{E}$

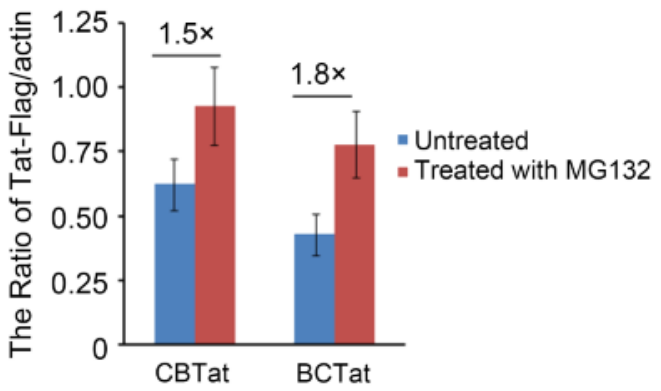

F

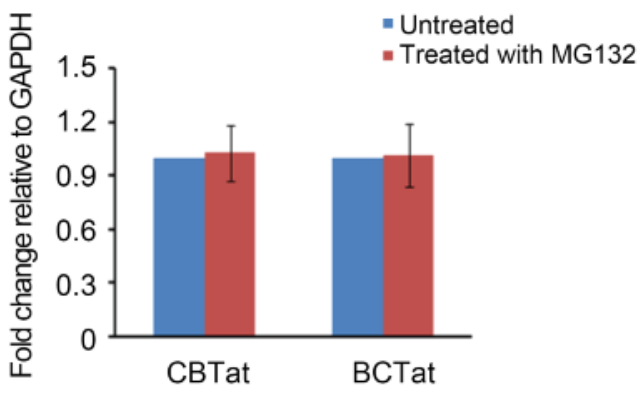

Figure 3. The proteasome-dependent Tat degradation pathway was influenced by the carboxyl-terminal region of Tat. (A, D) HEK293T cells were transfected with Tat-Flag, and treated with (+) or without (-) MG132. Cell lysates were immunoblotted with anti-Flag or anti- $\beta$-actin antibodies. (B, E) Quantification of the results in Figure 3A and 3D. Bars represent the relative ratios of Tat-Flag with respect to $\beta$-actin levels. (C, F) Quantitative real-time PCR analysis of gene expression in HEK293T cells transfected with Tat-Flag and treated with (+) or without (-) MG132. GAPDH was used for normalization. Two-tailed Student's $t$-tests were used to assess differences. Means and standard deviations were derived from three independent biological replicates.

assessed by western blotting (Figure 3B). The increases in CTat86, CTat72, BTat86, BTat72, BC-Tat, and CBTat by MG132 treatment were 3.8-fold, 4.5 -fold, 4.1 fold, 6.4-fold, 1.8-fold, and 1.5-fold, respectively (Figure $3 \mathrm{~B}$ and $3 \mathrm{E}$ ). Based on a quantitative real-time PCR analysis, we found that the mRNA levels of Tat and its mutants did not change significantly after MG132 treatment (Figure 3C and 3F). The fold change in Tat-Flag after MG132 treatment reflected the sensitivity of Tat to the proteasomal-dependent degradation pathway. Specifically, more stable Tat corresponded to a lower fold change after proteasome inhibitor treatment. Our results indicated that the degree of fold change was consistent with the stability of Tat. Therefore, the proteasome-dependent Tat degradation pathway was influenced by the carboxyl-terminal region of Tat.

\section{Transcriptional activity regulated by the} carboxyl-terminal region of Tat

Transactivation activity differs between full-length B-Tat and the truncated variant Tat86 (Campbell et al., 2005). We thus systematically analyzed the effects of the carboxyl-terminal regions of B-Tat and C-Tat on transactivation activity. We overexpressed Tat-Flag in $293 \mathrm{~T}$ cells co-transfected with a Photinus luciferase reporter plasmid containing the LTR, i.e., the HIV-1 promoter. When normalized for constitutive Renilla luciferase expression using a plasmid carrying the SV40 promoter, we observed that $\mathrm{C}$-Tat was a significantly stronger transactivator of LTR expression (Figure 4A), consistent with the results of Roof et al. (2002). Overall, B-Tat, CTat, and their truncated mutants were all able to promote the transactivation of LTR, but CTat101 was slightly 
more efficient with respect to LTR transactivation than CTat86 and substantially more efficient than CTat 72 . Moreover, BTat 86 was also slightly more efficient with respect to LTR transactivation than $\mathrm{BTat} 72$. These results implied that the carboxyl-terminal region may regulate Tat-mediated transactivation of the LTR region by affecting stability.

To determine the effects of B-Tat and C-Tat on NF- $\mathrm{BB}$ activation, luciferase reporter assays were performed using a dual-luciferase reporter assay system by transient transfection of the vector $3 \kappa \mathrm{B}-\mathrm{LUC}$ and pRL-TK in HEK293T cells. As shown in Figure 4B, C-Tat activated $\mathrm{NF}-\kappa \mathrm{B}$ more efficiently than B-Tat and the truncated mutants of Tat had a slight effect on Tat-mediated NF$\kappa \mathrm{B}$ activation. In addition, we examined the effect of the carboxyl-terminal region of Tat on transcriptional activity in Jurkat cells, and observed similar results to those using HEK293T cells (data not shown).

\section{DISCUSSION}

In this study, we found that NL4-3 Tat and 1084i Tat showed different stabilities. Based on an analysis of truncated forms of Tat, we demonstrated that the carboxylterminal region regulates stability. We found that $1084 \mathrm{i}$ Tat (subtype C) was more stable than NL4-3 Tat (subtype B), consistent with the results of Desfosses et al. (2005). Therefore, it is possible that subtype $\mathrm{C}$ is more stable than subtype B.

It has been reported that C-Tat is a significantly stronger transactivator of LTR expression than B-Tat (Desfosses et al., 2005). The mechanism underlying differ-

A

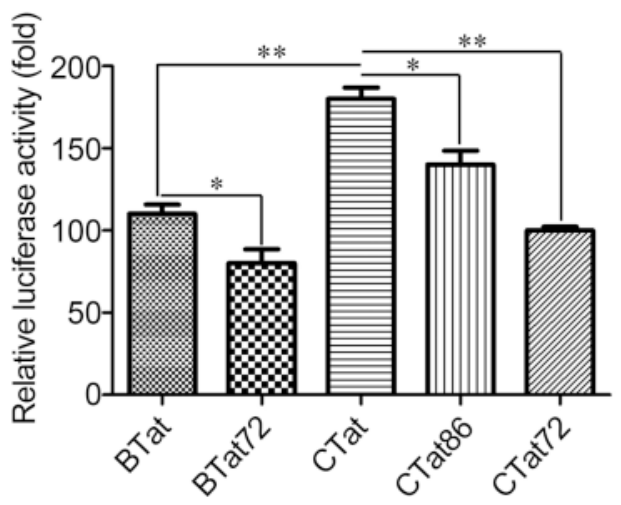

ences in transactivation ability between clades B and C Tat is not clear. The N-terminal, cysteine-rich, and core regions of Tat form the so-called transactivation domain, which is primarily responsible for P-TEFb binding. The neighboring basic domain (residues $49-57$ in HIV-1 Tat) is essential for regulating TAR RNA binding. Thus, the carboxyl-terminal region of Tat is not directly involved in the Tat-mediated transactivation of the LTR. Figure 4A shows that the Tat-mediated transactivation of the LTR was regulated by the carboxyl-terminal region of Tat. Thus, it is possible that the differences in transactivation between Tat truncated forms result from differences in stability according to the carboxyl-terminal region. In view of the amino acid variation among cladespecific Tat proteins, there may be multiple mechanisms underlying the differences in transactivation between BTat and C-Tat. According to our results, the difference in stability between B-Tat and C-Tat may be one explanation.

HIV-1 Tat activates NF- $\kappa B$ by hijacking the inhibitor $\mathrm{I} \kappa \mathrm{B}-\alpha$ and preventing repressor binding to the NF- $\kappa \mathrm{B}$ complex, and the basic domain of Tat is required for the I $\kappa \mathrm{B}-\alpha$ association (Fiume et al., 2012). In this study, it was surprising that $\mathrm{C}-\mathrm{Tat}$ was a stronger activator of NF$\kappa \mathrm{B}$ than B-Tat. As the carboxyl-terminal region of Tat had a slight effect on Tat-mediated NF- $\kappa \mathrm{B}$ activation, we compared the basic domains of B-Tat and C-Tat and found a difference at the $57^{\text {th }}$ amino acid. The $57^{\text {th }}$ arginine and serine are highly conserved within both B-Tat and C-Tat (data not shown). Therefore, we hypothesized that the difference at the $57^{\text {th }}$ amino acid within the basic domain between B-Tat and C-Tat may explain the differ-

B

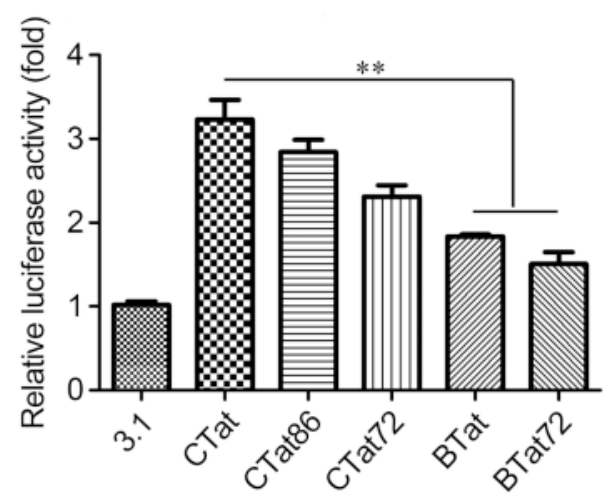

Figure 4. Transcriptional activity regulated by the carboxyl-terminal region of Tat. (A) The effect of truncated forms of Tat on transactivity. HEK293T cells were co-transfected with the pLTR-luc transcriptional reporter plasmid and pcDNA3.1-Tat-Flag plasmid. After transfection for $48 \mathrm{~h}$, luciferase activity was measured. (B) NF-kB-dependent transactivation activity was measured by transient transfection of the 3kB-LUC plasmid and pcDNA3.1-Tat-Flag plasmid into HEK293T cells. After transfection for $48 \mathrm{~h}$, luciferase activity was measured. All samples were co-transfected with a SV40-promoter-containing Renilla luciferase plasmid as a control for normalizing transfection efficiency. ${ }^{*} P \leq 0.05,{ }^{*} P$ $\leq 0.01$. 
ent interactions of I $\kappa \mathrm{B}-\alpha$ with B-Tat and C-Tat, which contributes to the differences in NF- $\mathrm{BB}$ activation (we are currently examining this hypothesis).

In fact, the clade $C$ virus appears to be transmitted more efficiently than subtype $\mathrm{B}$, as evidenced by its predominance in the HIV-1 pandemic worldwide. In addition, clinical follow-up studies have revealed that subtype $\mathrm{C}$-infected individuals might develop AIDS more easily than those infected with other subtypes (Kanki et al., 1999). This appears to be related to biological differences between viruses, including rapid and high replication rates as well as more efficient transmission rates. Secreted Tat contributes to the spread of HIV-1 via its effect on the surface expression of CCR 5 and CXCR4 (Howcroft et al., 1993). Higher Tat stability may contribute to viral transcription and the surface expression of $\mathrm{CCR} 5$ and CXCR4. In addition, NF- $\mathrm{\kappa B}$ is a master regulator of pro-inflammatory genes and is upregulated in human immunodeficiency virus 1 infection. The mechanisms underlying NF- $\mathrm{KB}$ deregulation by HIV-1 are relevant for immune dysfunction in AIDS (Fiume et al., 2012). Therefore, the unique properties of clade $C$ may contribute to its efficient transmission.

\section{ACKNOWLEDGMENTS}

This work was supported by grants from the National Natural Science Foundation of China (No. 81571987 and $81371820)$ and the Ph.D. Candidate Research Innovation Fund of Nankai University (2015) (No. 68150003). We greatly appreciate the gift of infectious molecular clone HIV1084i provided by Dr. Charles Wood (University of Nebraska, Lincoln, USA).

\section{COMPLIANCE WITH ETHICS GUIDELINES}

The authors declare that they have no conflict of interest. This article does not contain any studies with human or animal subjects performed by any of the authors.

\section{AUTHOR CONTRIBUTIONS}

$\mathrm{XCZ}$ and XHK designed the experiments. XCZ, LYQ, DYZ, and DQ carried out the experiments. XCZ and CL analyzed the data. XCZ and XHK wrote the paper. All authors read and approved the final manuscript.

\section{REFERENCES}

Campbell GR, Watkins JD, Esquieu D, Pasquier E, Loret EP, Spector SA. 2005. The C terminus of HIV-1 Tat modulates the extent of CD178-mediated apoptosis of T cells. J Biol Chem, 280: 38376-38382.

Cohen J. 2012. The Many States Of HIV in America. Science, 337: 168-171.

Desfosses Y, Solis M, Sun Q, Grandvaux N, Van Lint C, Burny A,
Gatignol A, Wainberg MA, Lin R, Hiscott J. 2005. Regulation of human immunodeficiency virus type 1 gene expression by clade-specific Tat proteins. J Virol, 79: 9180-9191.

Essex M. 1999. Human immunodeficiency viruses in the developing world. Adv Virus Res, 53: 71-88.

Fiume G, Vecchio E, De Laurentiis A, Trimboli F, Palmieri C, Pisano A, Falcone C, Pontoriero M, Rossi A, Scialdone A, Fasanella Masci F, Scala G, Quinto I. 2012. Human immunodeficiency virus-1 Tat activates NF-kappaB via physical interaction with IkappaB-alpha and p65. Nucleic Acids Res, 40: 3548-3562.

Gatignol A, Jeang KT. 2000. Tat as a transcriptional activator and a potential therapeutic target for HIV-1. Adv Pharmacol, 48: 209-227.

Geretti AM. 2006. HIV-1 subtypes: epidemiology and significance for HIV management. Curr Opin Infect Dis, 19: 1-7.

Gibellini D, Vitone F, Schiavone P, Re MC. 2005. HIV-1 tat protein and cell proliferation and survival: a brief review. New Microbiol, 28: 95-109.

Grisson RD, Chenine AL, Yeh LY, He J, Wood C, Bhat GJ, Xu W, Kankasa C, Ruprecht RM. 2004. Infectious molecular clone of a recently transmitted pediatric human immunodeficiency virus clade $C$ isolate from Africa: evidence of intraclade recombination. J Virol, 78: 14066-14069.

Howcroft TK, Strebel K, Martin MA, Singer DS. 1993. Repression of MHC class I gene promoter activity by two-exon Tat of HIV. Science (New York, N.Y.), 260: 1320-1322.

Kanki PJ, Hamel DJ, Sankale JL, Hsieh CC, Thior I, Barin F, Woodcock SA, Gueye-Ndiaye A, Zhang E, Montano M, Siby T, Marlink R, NDoye I, Essex ME, MBoup S. 1999. Human immunodeficiency virus type 1 subtypes differ in disease progression. Journal of Infectious Diseases, 179: 68-73.

Karn J. 1999. Tackling Tat. J Mol Biol, 293: 235-254.

Lata S, Ali A, Sood V, Raja R, Banerjea AC. 2015. HIV-1 Rev downregulates Tat expression and viral replication via modulation of NAD(P)H:quinine oxidoreductase 1 (NQO1). Nat Commun, 6: 7244 .

Lopez-Huertas MR, Callejas S, Abia D, Mateos E, Dopazo A, Alcami J, Coiras M. 2010. Modifications in host cell cytoskeleton structure and function mediated by intracellular HIV-1 Tat protein are greatly dependent on the second coding exon. Nucleic Acids Res, 38: 3287-3307.

Loret EP, Georgel P, Johnson WC, Jr., Ho PS. 1992. Circular dichroism and molecular modeling yield a structure for the complex of human immunodeficiency virus type 1 trans-activation response RNA and the binding region of Tat, the trans-acting transcriptional activator. Proc Natl Acad Sci U S A, 89: 9734-9738.

Mishra M, Vetrivel S, Siddappa NB, Ranga U, Seth P. 2008. Clade-specific differences in neurotoxicity of human immunodeficiency virus-1 B and C Tat of human neurons: significance of dicysteine C30C31 motif. Ann Neurol, 63: 366-376.

Ott M, Emiliani S, Van Lint C, Herbein G, Lovett J, Chirmule N, McCloskey T, Pahwa S, Verdin E. 1997. Immune hyperactivation of HIV-1-infected T cells mediated by Tat and the CD28 pathway. Science, 275: 1481-1485.

Passiatore G, Rom S, Eletto D, Peruzzi F. 2009. HIV-1 Tat C-terminus is cleaved by calpain 1: implication for Tat-mediated neurotoxicity. Biochim Biophys Acta, 1793: 378-387.

Rana TM, Jeang KT. 1999. Biochemical and functional interactions between HIV-1 Tat protein and TAR RNA. Arch Biochem Biophys, 365: 175-185.

Roof P, Ricci M, Genin P, Montano MA, Essex M, Wainberg MA, Gatignol A, Hiscott J. 2002. Differential regulation of HIV-1 clade-specific B, C, and E long terminal repeats by NF-kappaB 
and the Tat transactivator. Virology, 296: 77-83.

Saiyed ZM, Gandhi N, Agudelo M, Napuri J, Samikkannu T, Reddy PVB, Khatavkar P, Yndart A, Saxena SK, Nair MPN. 2011. HIV-1 Tat upregulates expression of histone deacetylase2 (HDAC2) in human neurons: Implication for HIV-associated neurocognitive disorder (HAND). Neurochemistry International, 58: 656-664.

Saxena SK, Tiwari S, Nair MPN. 2012. A Global Perspective on HIV/AIDS. Science, 337: 798-798.

Sivakumaran H, van der Horst A, Fulcher AJ, Apolloni A, Lin MH, Jans DA, Harrich D. 2009. Arginine methylation increases the stability of human immunodeficiency virus type 1 Tat. J Virol, 83: 11694-11703.

Smith SM, Pentlicky S, Klase Z, Singh M, Neuveut C, Lu CY, Reitz MS, Jr., Yarchoan R, Marx PA, Jeang KT. 2003. An in vivo replication-important function in the second coding exon of Tat is constrained against mutation despite cytotoxic T lymphocyte selection. J Biol Chem, 278: 44816-44825.

Xiao H, Neuveut C, Benkirane M, Jeang KT. 1998. Interaction of the second coding exon of Tat with human EF-1 delta delineates a mechanism for HIV-1-mediated shut-off of host mRNA translation. Biochem Biophys Res Commun, 244: 384-389. 